\title{
A PRACTICAL METHOD FOR QUANTIFICATION OF PLEURAL EFFUSION BY USG
}

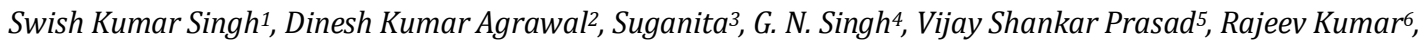
Ajay Kumar7, Anjali Verma ${ }^{8}$

1 Post Graduate, Department of Radiodiagnosis, Patna Medical College \& Hospital, Patna.

${ }^{2}$ Post Graduate, Department of Radiodiagnosis, Patna Medical College \& Hospital, Patna.

${ }^{3}$ Post Graduate, Department of Dermatology, Leprology \& Venereology, Patna Medical College \& Hospital, Patna.

4 Professor and HOD, Department of Radiodiagnosis, Patna Medical College \& Hospital, Patna.

5 Professor, Department of Radiodiagnosis, Patna Medical College \& Hospital, Patna.

${ }^{6}$ Associate Professor, Department of Radiodiagnosis, Patna Medical College \& Hospital, Patna.

${ }^{7}$ Assistant Professor, Department of Radiodiagnosis, Patna Medical College \& Hospital, Patna.

${ }^{8}$ Assistant Professor, Department of Physiology, Patna Medical College \& Hospital, Patna.

\section{ABSTRACT}

\section{OBJECTIVE}

The aim of this study is to find a correlation between pleural separation and amount of aspirated effusion.

\section{METHODS}

Total 20 adult patients with 25 effusions were taken into the study with chest x-ray showing homogeneous opacity in either one or both of the lung field, which was confirmed on USG. Only uncomplicated pleural effusion were taken into study. Effusion with septations or encysted effusion or pyothorax were excluded from the study.

\section{RESULTS}

The separation between two pleura was measured in millimeters and aspirated effusion in milliliters. A positive correlation was noted between these two measurements and relationship is given by a simplified equation.

\section{CONCLUSION}

By using this simple equation, we can quantify the pleural fluid quickly in day-to-day practice as well as ICU setting, which can be a useful guide for planning and management for aspiration.

\section{CONSENT}

As all the patients were adult and fully conscious, informed consent was taken from all of them.

\section{KEYWORDS}

Pleural Effusion, Aspiration.

HOW TO CITE THIS ARTICLE: Singh SK, Agrawal DK, Suganita, et al. A practical method for quantification of pleural effusion by USG. J. Evolution Med. Dent. Sci. 2016;5(8):354-356, DOI: 10.14260/jemds/2016/79

\section{INTRODUCTION}

Pleural effusion tends to be used as a collective term denoting a collection of fluid within the pleural cavity. This can be further divided into exudates and transudates depending on the biochemical analysis of aspirated pleural fluid. Essentially, it represents any pathological process which overwhelms the pleura's ability to reabsorb fluid whether it is due to excess production or impaired reabsorption.

Although, the term pleural effusion is used to include all kinds of fluid that may accumulate in the pleural cavity. In clinical practice it usually excludes non-transudate types of fluid, which can have distinctly different etiologies despite appearing identical on radiography (e.g. Pyothorax, Chylothorax, Hemothorax).(1)

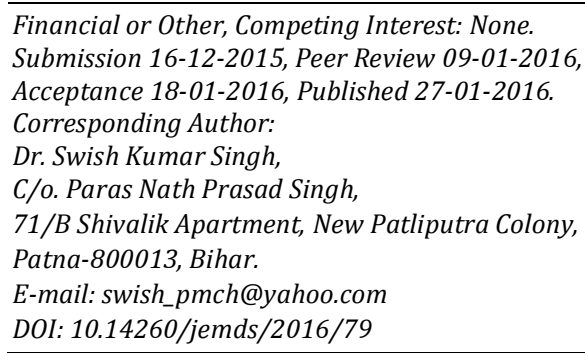

The ultrasound image of pleural effusion is characterized by an echo-free space between the visceral and parietal pleura.(1) USG chest shows reliability for diagnosis of pleural effusions than bedside chest $\mathrm{x}$-ray.(2,3,4) Ultrasound rules out other etiologies such as atelectasis, consolidation, mass or an elevated hemi-diaphragm, takes less time than radiographic methods and can be repeated serially at the bedside. Thoracentesis performed under ultrasound showed reduced rates of complications. $(5,6,7,8)$

Effusion tends to compromise the ventilation by compressing the lung tissue and can cause breathlessness. Also, particularly in ICU setting with mechanical ventilation relatively lesser amount of effusion can cause reduced lung function due to development of micro-atelectasis in dependent areas, which has significant effect on patient's outcome.

Quantification of fluid in the pleural cavity is an important step in management. In the case of a small amount of pleural fluid, the benefit of puncture should be weighed against risk of complications like pneumothorax or bleeding. ${ }^{(9)}$ But to calculate the amount of fluid with formula for volume applied as in other cystic lesions where shape is more or less spherical or ovoid, because thorax is a large cavity with lung in the central part of cavity. 
Few methods are devised for quantification, but most of them are very complex. So a different but quick and simplified method yet clinically acceptable is needed for bedside application, which will be used in this study.

\section{MATERIALS AND METHODS}

Total 20 adult patients were taken in the study with 25 pleural effusions referred from the Department of Medicine for USG chest with guided aspiration. All patients showing homogeneous opacity in the either or both of lung field in preliminary chest $\mathrm{x}$-ray and later confirmed on USG. Underlying lung pathology is not taken into consideration and only uncomplicated pleural effusion are taken into study. Effusion with septations or encysted effusion or pyothorax are excluded from the study. Effusions with less than $10 \mathrm{~mm}$ separation were also excluded from the study.

USG along with aspiration was done in the Emergency USG unit of Department of Radiology, Patna Medical College and Hospital, Patna on GE Logiq P3 USG machine with curvilinear phased array and linear high resolution transducer probe.

We used the 3-5 MHz curvilinear or phased array probe to view the pleural effusion and the surrounding landmarks. These include visualizing the lung within the pleural effusion, the diaphragm, the liver on the right side and the spleen on the left side. Use of the lower frequency 3-5 $\mathrm{MHz}$ probe offers a wider depth of field and a more global view of the lung and the effusion.(10,11) The separation between visceral and parietal pleura is measured in millimetres $(\mathrm{mm})$ in the supine position in mid-axillary line at the end of expiration which shows maximal separation.

A more focused and detailed view of the thoracic space can then be obtained by using the higher frequency $10 \mathrm{MHz}$ linear array probe that allows improved imaging at a more superficial depth. 12 This technique can often allow one to more precisely measure the depth of the effusion from the outer parietal chest pleura to the lung, particularly when effusion is small. One can refer to this fluid depth as the safety zone, in which the needle should be positioned during the procedure. Pleural fluid was aspirated in the sitting position with the help of 20-G needle and triway.

All cases were completely aspirated under USG guidance and terminated when no fluid could be further aspirated. Incomplete aspiration or separation more than $1 \mathrm{~cm}$ after 1 hour of aspiration was excluded from the study. The aspirated fluid volume is measured in calibrated container. The statistical analyses for correlation between pleural separation and aspirated fluid were done online.

\section{RESULTS}

Total 20 patients with 25 effusions were evaluated. Five patients showed bilateral presence of effusion. The mean separation was $41.16 \mathrm{~mm}$ with maximum separation $75 \mathrm{~mm}$ and minimum separation $15 \mathrm{~mm}$. The mean aspirated fluid volume was $809.6 \mathrm{mls}$. with maximum and minimum volume was 1800 and $280 \mathrm{ml}$. respectively. By calculating correlation coefficient a significant correlation was seen between the pleural separation and aspirated effusion volume $(\mathrm{r}=0.8565$, $\mathrm{r}^{2}=0.7336$, $\mathrm{P}$-value is $<0.00001$ which is significant at $\mathrm{p}<0.05$ ). The volume can be calculated by the below mentioned formula.

$\mathrm{V}(\mathrm{ml})=20 \times \operatorname{Sep}(\mathrm{mm})$

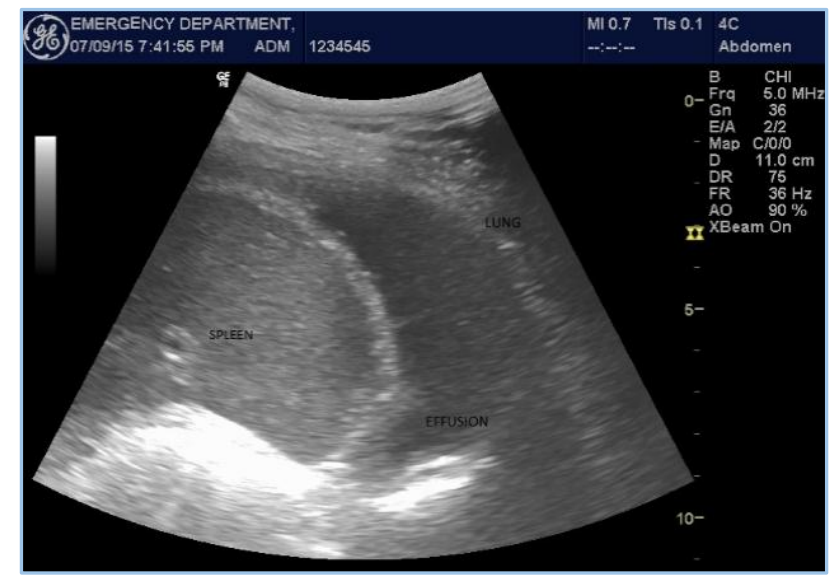

Fig. 1: Pleural effusion is denoted by anechoic space

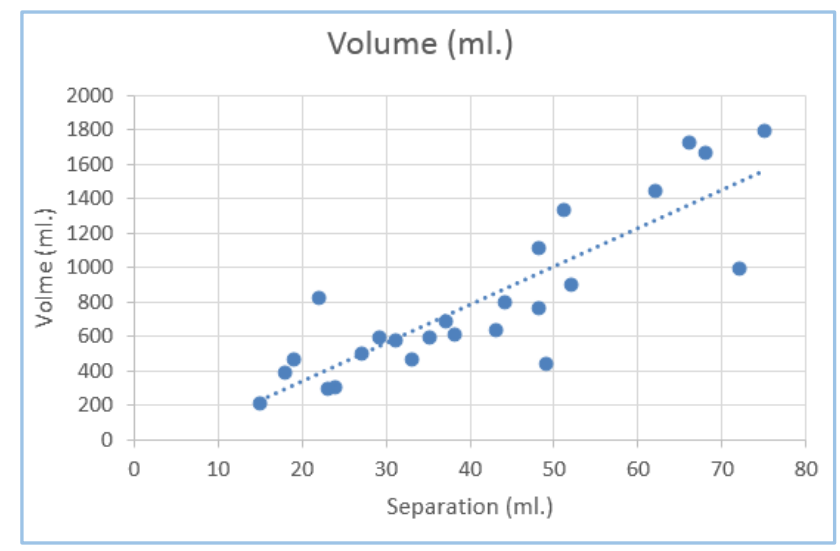

\section{Fig. 2: The relationship between pleural Separation and aspirated effusion}

\section{DISCUSSION}

Ultrasound can be used to accurately estimate the amount of effusion present in the chest cavity and to decide when and how much fluid should optimally be removed during the thoracentesis procedure, particularly in the ICU setting. Although, this study is done in the ambulatory patients, it can be applied in ventilated patient also.

The simplest method for estimation of pleural effusion is classifying it as minimal, if the hypoechoic space is seen only at the costophrenic angle; small if it covers the costophrenic angle but limited within the image formed by the transducer; moderate if the space is larger than the image but limited within two images; and large or massive if it is larger than two images formed by the transducer. ${ }^{11}$ But being a qualitative classification, this does not give the amount of effusion in each category.

There are also a number of sizing guides to effusions, which vary significantly. Lichtenstein's PLAPS index measures the distance between the pleural line and the lung line at the posterolateral point. It is measured at its greatest size (i.e. in expiration). ${ }^{13}$

\begin{tabular}{|c|c|}
\hline PLAPS Index (cm.) & Effusion Vol. (mls.) \\
\hline 0.3 & $15-30$ \\
\hline 1 & $75-150$ \\
\hline 2 & $300-600$ \\
\hline 3.5 & $1500-2500$ \\
\hline \multicolumn{2}{|c|}{ Table 1 } \\
\hline
\end{tabular}


Another method for the fluid volume calculation by measuring the maximum perpendicular distance between the surface and the chest wall.

The scan is performed with the patient in the supine position at maximum inspiration. The measurement is made right above the diaphragm. A $20 \mathrm{~mm}$ extension corresponds to an average volume of $380 \mathrm{ml}( \pm 130 \mathrm{ml})$. A $40 \mathrm{~mm}$ extension corresponds to an average volume of $1000 \mathrm{ml}( \pm 330 \mathrm{ml})$ as shown on Table 2.

\begin{tabular}{|c|c|c|}
\hline $\begin{array}{c}\text { Separation } \\
\text { in } \mathbf{~ m m}\end{array}$ & $\begin{array}{c}\text { Effusion equivalent } \\
\text { volume }(\mathbf{m l})\end{array}$ & $\begin{array}{c}\text { Variation } \\
\text { (ml) }\end{array}$ \\
\hline 0 & 8 & $0-90$ \\
\hline 5 & 80 & $20-170$ \\
\hline 10 & 170 & $50-300$ \\
\hline 15 & 270 & $90-420$ \\
\hline 20 & 380 & $150-660$ \\
\hline 30 & 550 & $210-1,060$ \\
\hline 40 & 1,000 & $490-1,670$ \\
\hline 50 & 1,420 & $650-1,840$ \\
\hline \multicolumn{3}{|c|}{ Table 2 } \\
\hline
\end{tabular}

These are approximate values and needs to be memorized for individual measurements. In this study, a simple equation is described between the volume of the effusion and the separation distance between the lung and the outer parietal pleura as. ${ }^{9}$

$\mathrm{V}(\mathrm{ml})=20 \times \operatorname{Sep}(\mathrm{mm})$

Although, the measured volume seems to be a linear function of separation between pleurae, it is not true completely. It tends to give error in calculation of very large amount of effusion due to other factors, e.g. the volume can be underestimated due to passive collapse of lower lobe in large effusions. Thoracic shape, size and volume may also affect the measurement of fluid. To accurately measure the extreme ends of amount of effusion a different reliable method should be applied and for affirmation a larger study is needed to establish the accuracy. However, because of its easy and simple calculation this equation can be easily applied in bedside setting as a quick method.

\section{CONCLUSION}

By using this simple equation we can quantify the pleural fluid quickly in day-to-day practice as well as ICU setting, which gives acceptable level of accuracy with small variations and can be a useful guide for planning and management for aspiration.

\section{REFERENCES}

1. http://radiopaedia.org/articles/pleural-effusion.

2. Eibenberger KL, Dock WI, Ammann ME, et al. (1994) Quantification of pleural effusions: sonography versus radiography. Radiology 191:681-684.

3. Sahn SA (1999). Pleural disease in critically ill patient. In: Irwin RS, Cerra FB, Rippe JM (eds). Intensive Care Med Lippincott Raven, Philadelphia, pp 710-727.

4. Coppage L, Jolles H, Henry DA (1995). Imaging of the chest in the intensive care setting. In: Shoemaker WC, Ayres SM, Grenvik A, Holbrook PR (eds) Textbook of critical care. Saunders, Philadelphia, pp 332-347.

5. Fartoukh M, Azoulay E, Galliot R, et al. (2002). Clinically documented pleural effusions in medical ICU patients. How useful is routine thoracentesis? Chest 121:178-184.

6. Lichtenstein D, Hulot JS, Rabiller A, et al. (1999). Feasibility and safety of ultrasound-aided thoracentesis in mechanically ventilated patients. Intensive Care Med 25:955-958.

7. Mayo PH, Goltz HR, Tafreshi M, et al. (2004). Safety of ultrasound-guided thoracentesis in patients receiving mechanical ventilation. Chest 125:1059-1062.

8. Jones PW, Moyers JP, Rogers JT, et al. (2003). Ultrasoundguided thoracentesis. Is it a safer method? Chest 123:418-423.

9. Balik M, Plasil P, Waldauf P, et al. "Ultrasound estimation of volume of pleural fluid in mechanically ventilated patients."

Intensive Care Medicine, vol 32, no 2, pp 318-321, 2006.

10. http://www.hindawi.com/journals/isrn/2012/676524/

11. Feller-Kopman D. "Ultrasound-guided thoracentesis." Chest, vol 129, no 6, pp 1709-1714, 2006.

12. Turner J and Dankoff J. "Thoracic ultrasound.” Emergency Medicine Clinics of North America, vol 30, no 2, pp 451-473, 2012.

13. Silva COS, Macedo AG. Pneumologia. In: Prado FC, Ramos JA, Valle JR, editors. Atualização terapêutica. $2^{\underline{a}}$ ed. São Paulo: Artes Médicas, 2003;1446-1452. 